\title{
Tracing the legacy of the early Hainan Islanders- a perspective from mitochondrial DNA
}

\author{
Min-Sheng Peng ${ }^{1,3,5+}$, Jun-Dong He $\mathrm{He}^{1,2,3+}$, Hai-Xin Liu ${ }^{1,2,6}$, Ya-Ping Zhang ${ }^{1,3,4^{*}}$
}

\begin{abstract}
Background: Hainan Island is located around the conjunction of East Asia and Southeast Asia, and during the Last Glacial Maximum (LGM) was connected with the mainland. This provided an opportunity for the colonization of Hainan Island by modern human in the Upper Pleistocene. Whether the ancient dispersal left any footprints in the contemporary gene pool of Hainan islanders is debatable.

Results: We collected samples from $285 \mathrm{Li}$ individuals and analyzed mitochondrial DNA (mtDNA) variations of hypervariable sequence I and II (HVS-I and II), as well as partial coding regions. By incorporating previously reported data, the phylogeny of Hainan islanders was reconstructed. We found that Hainan islanders showed a close relationship with the populations in mainland southern China, especially from Guangxi. Haplotype sharing analyses suggested that the recent gene flow from the mainland might play important roles in shaping the maternal pool of Hainan islanders. More importantly, haplogroups $\mathrm{M} 12, \mathrm{M} 7 \mathrm{e}$, and $\mathrm{M} 7 \mathrm{C} 1^{*}$ might represent the genetic relics of the ancient population that populated this region; thus, 14 representative complete mtDNA genomes were further sequenced.

Conclusions: The detailed phylogeographic analyses of haplogroups $M 12, M 7 e$, and $M 7 \mathrm{Cl}^{*}$ indicated that the early peopling of Hainan Island by modern human could be traced back to the early Holocene and/or even the late Upper Pleistocene, around 7 - $27 \mathrm{kya}$. These results correspond to both Y-chromosome and archaeological studies.
\end{abstract}

\section{Background}

Hainan Island, the second largest island of China, is located in the Beibu Bay (Gulf of Tonkin) and separated from Guangdong's Leizhou Peninsula to the north by the Qiongzhou Strait (Figure 1). During the Last Glacial Maximum (LGM), around 19 - 26.5 kya (thousand years ago) [1], Hainan Island was connected with mainland southern China and northern Vietnam, as the sea level was around $80-100 \mathrm{~m}$ below present day [2,3]. Thus, Hainan Island might lay on one of the modern human northward migration routes from Southeast Asia to East Asia and it is likely that Hainan islanders may maintain certain ancient footprints of these dispersals [4]. This scenario has been supported by some recent archaeological evidence, which suggested that Hainan Island might

\footnotetext{
* Correspondence: zhangyp@mail.kiz.ac.cn

† Contributed equally

'State Key Laboratory of Genetic Resources and Evolution, Kunming Institute of Zoology, Chinese Academy of Sciences, Kunming, P.R. China
} Full list of author information is available at the end of the article have been colonized by human in the Upper Pleistocene or the Upper Paleolithic period [5-8].

Due to the post-glacial sea level rising and the formation of the Qiongzhou Strait, Hainan Island has been isolated from the mainland for at least 6 thousand years $[3,9]$. Presently, Hainan Island is home to people with many different languages and/or cultures. Compared with other ethnic/linguistic groups (e.g. Lingao, Han, and Hmong) - the recent immigrants from mainland southern China [10], Li (Hlai) people were suggested to be the earliest settlers, having arrived in Hainan Island at least 3 kya [11]. In terms of linguistic analyses, the Hlai language, used by the Li people was suggested to split from other languages within the Tai-Kadai (Daic) family $\sim 3-4$ kya [12]. Meanwhile, some current Li populations still maintain some ancient cultures of the Neolithic, e.g. bark cloth and original ceramic making [10]. Therefore, colonization of Hainan Island by the ancestors of the Li people can be at least traced back to the Neolithic period ( $2-6$ kya) $[11,13]$. However, whether the ancestor of the modern human had settled
C Biomed Central 


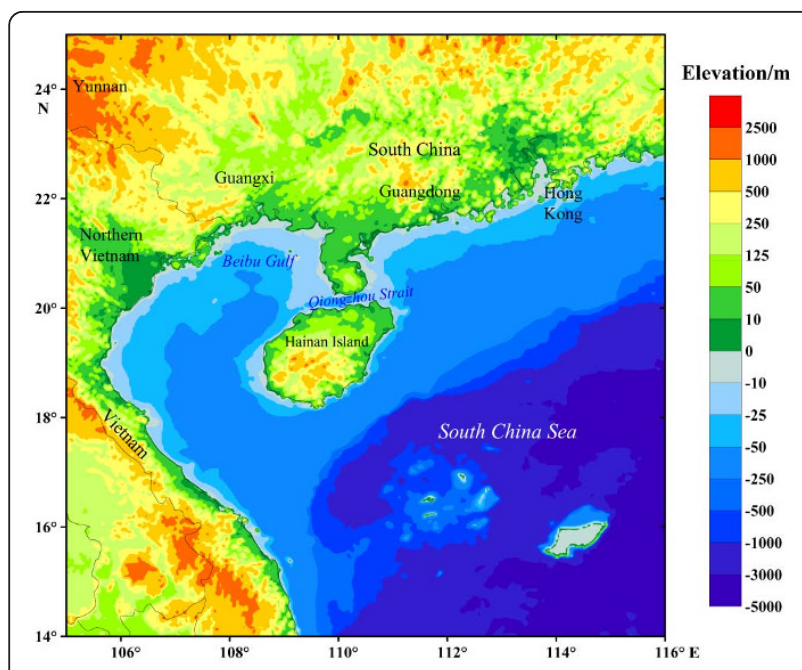

Figure 1 Map of Hainan Island and its surrounding regions, showing elevation relative to modern sea level. Map outline was kindly provided by YT. Yao, CAS Key Laboratory of Marginal Sea Geology, South China Sea Institute of Oceanology, Guangzhou [3].

in this region in the Upper Pleistocene and contributed to the gene pool of modern Li populations in Hainan Island is unclear.

To depict the prehistoric peopling events in this region, human genetic approaches based on the uniparental genetic systems - mitochondrial DNA (mtDNA) and the nonrecombining region of the $\mathrm{Y}$ chromosome (NRY) have been widely adopted [14]. By analyzing the dominant NRY haplogroups (paragroups) O1a* and O2a* in Hainan aborigines (five Li populations and one Cun population), Li et al. suggested that Hainan aborigines had been isolated at the entrance to East Asia for $\sim 20$ thousand years [4]. However, because of the relatively poor resolution of phylogeny based on limited numbers of Y-SNPs, the candidate founders of the ancient dispersal were still ambiguous. Moreover, in their later work about $\mathrm{O} 1 \mathrm{a}$ *, wide connections among the populations around the Beibu Bay (i.e. Guangxi and Hainan) and other populations from southern China and Southeast Asia were observed [15]. This implies that the effect of some recent gene flows between Hainan islanders and the populations in the mainland could not be ignored.

In this study, we adopted mtDNA analyses to trace the ancient peopling of Hainan Island in a maternal perspective, because: 1) the phylogeny of mtDNA in context of East Asian and Southeast Asian has been improved thanks to large scale complete mtDNA genome sequencing [16-28]; 2) mtDNA data of many ethnic/linguistic groups in the neighboring regions of Hainan Island (i.e. southern China [29-36] and northern Vietnam [23,37]) have been reported. Given that the maternal structures of the Li populations were poorly characterized in previous work [30], we collected new samples from $285 \mathrm{Li}$ individuals. With comprehensive phylogeographic analyses based on complete mtDNA genomes sequencing, we identified some potential candidate markers for the early peopling of Hainan Island, which could be traced back to $\sim 7$ - 27 kya.

\section{Results}

\section{The phylogeny of mtDNA in Hainan Island}

Hypervariable sequence (HVS) analysis and partial coding region testing indicated that all mtDNA lineages of the $285 \mathrm{Li}$ individuals were unambiguously assigned into the previously defined haplogroups in East and Southeast Asians (see Additional file 1). The predominant haplogroups in southern China and Southeast Asia: haplogroups B, F, and M7 together account for 69\%, 71\%, and $63 \%$ of the maternal gene pools of the populations Li-BT, Li-LD, and Li-QZ, respectively (Table 1 ). The prevailing haplogroups in northern China, such as haplogroups A, D4, G, and Z, were rare or even absent in the three Li populations. Meanwhile, the previously reported 162 sequences from five populations (Li-TZ, Jiamao, Cun, Danga, and Lingao) in Hainan Island [30] were reevaluated and incorporated into further analyses. The skeleton of the resulting phylogeny of 447 individuals from Hainan Island was constructed (Figure 2). The mtDNA haplogroups profiles of the Hainan islanders were similar to the patterns observed in the populations from the mainland southern China and northern Vietnam (Table 1). However, haplogroups M12 and M7e had higher frequencies ( $6.3 \%$ and $\sim 4.5 \%$, respectively) in the Hainan islanders than those of the populations in the mainland, whose average were less than $1 \%$.

\section{Comparison of the Hainan islanders with other populations in the mainland}

To compare the Hainan Islanders with other populations in the mainland (see Additional file 2), the principal components (PC) analysis based on haplogroup frequencies (see Additional file 3) was performed (Figure 3). In the first PC, some Sinitic populations (Han-DG, HK, Hakka, and Chaoshan) clustered in one pole. In the other pole, except Lingao and Danga, most Hainan islanders were clustered with some populations from Guangxi, which were distinguished from the other populations in the mainland by the second PC. The genetic difference between Hainan islanders and populations from the mainland was statistically significant $(p<0.001$, Analysis of molecular variance, AMOVA), whereas the difference between the Li populations (Li-BT, Li-LD, Li-QZ, Li-TZ, and Jiamao) and non-Li populations (Cun, Danga, and Lingao) was not $(p=0.147 \pm 0.010$, AMOVA). Then, we used the regression method to estimate the contribution of each haplogroup to the PCs [38]. The haplogroups 
Table 1 mtDNA haplogroup frequencies in Hainan Island, Taiwan, mainland southern China, and Vietnam

\begin{tabular}{|c|c|c|c|c|c|c|c|c|c|c|c|c|c|c|c|c|c|}
\hline & Hainan & & & & & & & & Hainan & Taiwan & Guangxi & Guangdong & Hong & Yunnan- & $\mathrm{N}-$ & M- & Mainland \\
\hline Haplogroups & $\begin{array}{l}\text { Li-BT } \\
n=99\end{array}$ & $\begin{array}{l}\text { Li-LD } \\
n= \\
100\end{array}$ & $\begin{array}{l}\mathrm{Li}-\mathrm{QZ} \\
\mathrm{n}= \\
86\end{array}$ & $\begin{array}{l}\text { Li-TZ } \\
n= \\
34\end{array}$ & $\begin{array}{l}\text { Jiamao } \\
n=27\end{array}$ & $\begin{array}{l}\text { Cun } \\
\mathrm{n}= \\
30\end{array}$ & $\begin{array}{l}\text { Lingao } \\
n=31\end{array}$ & $\begin{array}{l}\text { Danga } \\
n= \\
40\end{array}$ & $\begin{array}{l}\text { Total } \\
\mathrm{n}= \\
447\end{array}$ & $\begin{array}{l}\text { Total } \\
n= \\
640\end{array}$ & $\begin{array}{l}\text { Total } \\
\mathrm{n}= \\
1111\end{array}$ & $\begin{array}{l}\text { Total } \\
n=546\end{array}$ & $\begin{array}{l}\text { Total } \\
\mathbf{n}=337\end{array}$ & $\begin{array}{l}\text { Total } \\
n=158\end{array}$ & $\begin{array}{l}\text { Total } \\
\mathrm{n}=326\end{array}$ & $\begin{array}{l}\text { Total } \\
\mathrm{n}=66\end{array}$ & $\begin{array}{l}\text { Total } \\
\mathrm{n}=2584\end{array}$ \\
\hline A & & & 1.16 & & & & & 5.00 & 0.67 & & 1.71 & 2.56 & 3.98 & 0.63 & 0.92 & & 2.01 \\
\hline$B^{*}$ & & & & 2.94 & 3.70 & 3.33 & 6.45 & 2.50 & 1.34 & & 1.08 & 0.55 & 0.80 & 1.90 & 0.92 & 4.55 & 1.04 \\
\hline$B 4^{*}$ & & 1.00 & & & 3.70 & & & & 0.45 & & 1.71 & 2.20 & 1.86 & 1.27 & 2.76 & 1.52 & 1.93 \\
\hline B4a & 2.02 & 1.00 & 5.81 & 8.82 & 11.11 & 13.33 & 3.23 & 7.50 & 4.92 & 15.63 & 6.03 & 5.13 & 2.65 & 4.43 & 3.37 & 1.52 & 4.80 \\
\hline B4b1 & 9.09 & 11.00 & 6.98 & 8.82 & & 3.33 & 3.23 & & 6.94 & 7.34 & 3.24 & 3.48 & 2.39 & 2.53 & 0.61 & & 2.71 \\
\hline$B 4 c 1 b$ & & & 2.33 & & 3.70 & 6.67 & & 7.50 & 1.79 & 3.91 & 0.72 & 2.75 & 2.39 & & 2.15 & 1.52 & 1.55 \\
\hline$B 4 C 2$ & & & & & & & & 2.50 & 0.22 & & 0.36 & 0.55 & & 3.16 & 1.23 & 4.55 & 0.74 \\
\hline B4g & 2.02 & & 1.16 & 2.94 & & & & & 0.89 & & 2.16 & 1.47 & 0.80 & 0.63 & 3.07 & & 1.78 \\
\hline B5a & 10.10 & 10.00 & 8.14 & 8.82 & & & & 17.50 & 8.28 & 5.16 & 7.92 & 4.40 & 5.57 & 5.70 & 11.66 & 3.03 & 7.04 \\
\hline B5b & & 1.00 & 1.16 & & 3.70 & & & & 0.67 & & 0.72 & 1.65 & & & 0.61 & 1.52 & 0.77 \\
\hline C & 6.06 & & 1.16 & & & 10.00 & 6.45 & 7.50 & 3.36 & & 4.32 & 2.38 & 3.71 & 6.96 & 3.68 & 3.03 & 3.87 \\
\hline D4 & & 2.00 & 2.33 & 2.94 & & 3.33 & & & 1.34 & 1.25 & 4.77 & 10.62 & 11.41 & 6.96 & 2.76 & 1.52 & 6.77 \\
\hline D5'6 & 7.07 & 3.00 & 3.49 & & & & & & 2.91 & 4.06 & 1.89 & 5.13 & 6.37 & 2.53 & 2.15 & 1.52 & 3.29 \\
\hline $\mathrm{E}$ & & & & & & & & & & 12.03 & & 0.18 & & & & & 0.04 \\
\hline$F^{*}$ & & & & 2.94 & & & 6.45 & & 0.67 & & 0.63 & 0.18 & & & & & 0.31 \\
\hline $\mathrm{F} 1^{*}$ & 3.03 & & 1.16 & & & & 3.23 & & 1.12 & & 2.07 & 3.48 & 1.59 & 4.43 & 2.15 & 1.52 & 2.44 \\
\hline F1a* & & 3.00 & 1.16 & & & & & & 0.89 & 2.19 & 4.05 & 4.95 & 3.71 & 3.16 & 7.36 & 9.09 & 4.68 \\
\hline F1a $1^{*}$ & 9.09 & 16.00 & 5.81 & & & 3.33 & 3.23 & 2.50 & 7.38 & 3.28 & 3.42 & 4.03 & 5.04 & 4.43 & 4.29 & 6.06 & 4.02 \\
\hline Fla1a & & 2.00 & 1.16 & & & & 3.23 & & 0.89 & & 3.51 & 3.11 & 2.92 & 2.53 & 5.83 & 9.09 & 3.72 \\
\hline F2 & 4.04 & 6.00 & 3.49 & & 25.93 & & 6.45 & 2.50 & 5.15 & 0.16 & 1.62 & 3.30 & 3.45 & 0.63 & 0.61 & & 2.01 \\
\hline F3 & 3.03 & & & & & & 3.23 & 2.50 & 1.12 & 8.44 & 3.96 & 3.48 & 2.12 & 5.70 & 0.92 & & 3.21 \\
\hline F4 & & & 1.16 & 5.88 & & 10.00 & 3.23 & & 1.57 & 11.25 & 0.72 & 0.92 & 0.53 & & 0.31 & & 0.62 \\
\hline G & & & & 8.82 & & 3.33 & 3.23 & 2.50 & 1.34 & 0.16 & 2.07 & 2.38 & 1.06 & 7.59 & 0.92 & 3.03 & 2.21 \\
\hline$M^{*}$ & & & & 2.94 & & & 3.23 & & 0.45 & & 2.88 & 0.92 & 3.18 & 3.16 & 3.37 & 7.58 & 2.71 \\
\hline M10 & 1.01 & & 1.16 & & & 3.33 & & 7.50 & 1.34 & 0.63 & 1.08 & 2.01 & 1.86 & 0.63 & 0.92 & & 1.32 \\
\hline M12 & 11.11 & 4.00 & 9.30 & 5.88 & 3.70 & & & 5.00 & 6.26 & 0.31 & 0.72 & 0.73 & & 3.16 & 1.53 & 1.52 & 0.89 \\
\hline M20 & & & 1.16 & & & & & & 0.22 & & 0.09 & 0.37 & & & 0.61 & & 0.19 \\
\hline M33 & & & & & & 3.33 & 9.68 & & 0.89 & & 1.17 & 0.92 & 1.33 & & 0.61 & & 0.97 \\
\hline M71 & & & & & & & 3.23 & & 0.22 & & 0.54 & 0.37 & 0.27 & 1.27 & 0.92 & 3.03 & 0.62 \\
\hline M74 & & 2.00 & & & & & 3.23 & & 0.67 & & 0.54 & 0.18 & 0.80 & 0.63 & & 3.03 & 0.50 \\
\hline$M 7 b^{*}$ & 5.05 & 3.00 & 3.49 & & 3.70 & 3.33 & 6.45 & & 3.36 & 11.56 & 6.75 & 4.95 & 5.84 & 9.49 & 5.83 & 6.06 & 6.27 \\
\hline M7b1 & 10.10 & 9.00 & 1.16 & 5.88 & 7.41 & 6.67 & 3.23 & 10.00 & 6.94 & 0.78 & 9.09 & 3.66 & 6.63 & 5.70 & 6.75 & 6.06 & 7.00 \\
\hline M7c1'2 & 3.03 & & 6.98 & 5.88 & & & & 2.50 & 2.68 & 6.56 & 1.89 & 2.56 & 1.33 & & 2.76 & 1.52 & 1.93 \\
\hline M7c3 & 6.06 & 1.00 & 2.33 & & & & & & 2.01 & & 1.44 & 1.83 & 1.59 & & 1.23 & & 1.39 \\
\hline
\end{tabular}


Table 1 mtDNA haplogroup frequencies in Hainan Island, Taiwan, mainland southern China, and Vietnam (Continued)

\begin{tabular}{|c|c|c|c|c|c|c|c|c|c|c|c|c|c|c|c|c|c|}
\hline M7c & & 2.00 & 4.65 & 2.94 & & & & & 1.57 & & 0.09 & & & & & & 0.04 \\
\hline M7e & 2.02 & 5.00 & 4.65 & 14.71 & & 13.33 & & & 4.47 & & 0.18 & & 0.53 & & 0.61 & & 0.23 \\
\hline M8a & 3.03 & 4.00 & 1.16 & 2.94 & 7.41 & 3.33 & 6.45 & & 3.13 & & 1.08 & 2.38 & 1.06 & & 0.92 & 1.52 & 1.28 \\
\hline M9a'b & & & 4.65 & & & & & & 0.89 & & 1.53 & 0.73 & 1.59 & 1.27 & 1.53 & 1.52 & 1.35 \\
\hline $\mathrm{N}^{*}$ & & & & & & & & & & & 0.99 & 0.18 & & 0.63 & 1.23 & & 0.66 \\
\hline N10 & & & & & & & 3.23 & & 0.22 & & 0.09 & 0.37 & 0.53 & & 0.61 & & 0.27 \\
\hline N9a & 2.02 & & 3.49 & 2.94 & & & 3.23 & 2.50 & 1.79 & 1.56 & 3.42 & 3.85 & 2.12 & & 3.37 & 1.52 & 3.06 \\
\hline$R^{*}$ & & & & & & 3.33 & 3.23 & 5.00 & 0.89 & & 1.08 & 0.18 & 1.59 & 1.27 & 0.92 & & 0.93 \\
\hline R11 & 1.01 & & 2.33 & & 3.70 & & & 2.50 & 1.12 & & 1.08 & 0.55 & 0.80 & & & & 0.70 \\
\hline R9* & & & & & & & & & & & 0.27 & & & 1.27 & 0.92 & 3.03 & 0.39 \\
\hline R9b & & 8.00 & 5.81 & 2.94 & 18.52 & 6.67 & & 2.50 & 4.92 & & 3.96 & 1.47 & 2.12 & 3.16 & 3.37 & 7.58 & 3.13 \\
\hline R9c & & 6.00 & & & 3.70 & & 3.23 & & 1.79 & 2.34 & 0.63 & 0.73 & 2.12 & 1.27 & 1.53 & 3.03 & 1.08 \\
\hline Y & & & & & & & & & & 1.41 & 0.36 & 0.37 & 0.53 & & & & 0.31 \\
\hline Z & & & & & & & & 2.50 & 0.22 & & 0.36 & 1.83 & 1.86 & 1.90 & 2.15 & & 1.20 \\
\hline $\begin{array}{l}\text { Haplotype } \\
\text { Diversities }\end{array}$ & 0.976 & 0.966 & 0.982 & 0.980 & 0.960 & 0.972 & 0.996 & 0.986 & 0.987 & 0.966 & 0.989 & 0.996 & 0.994 & 0.991 & 0.992 & 0.988 & - \\
\hline
\end{tabular}




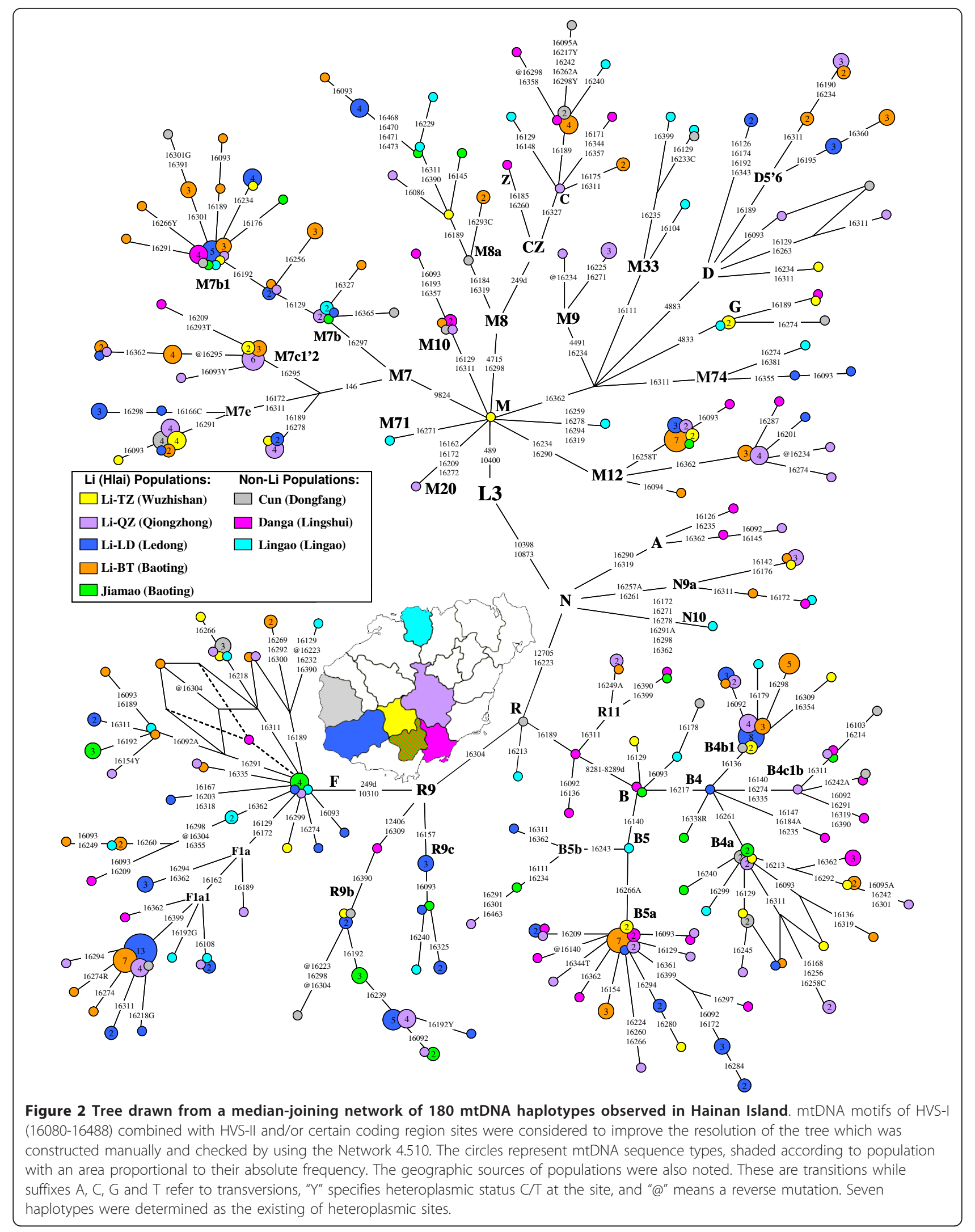




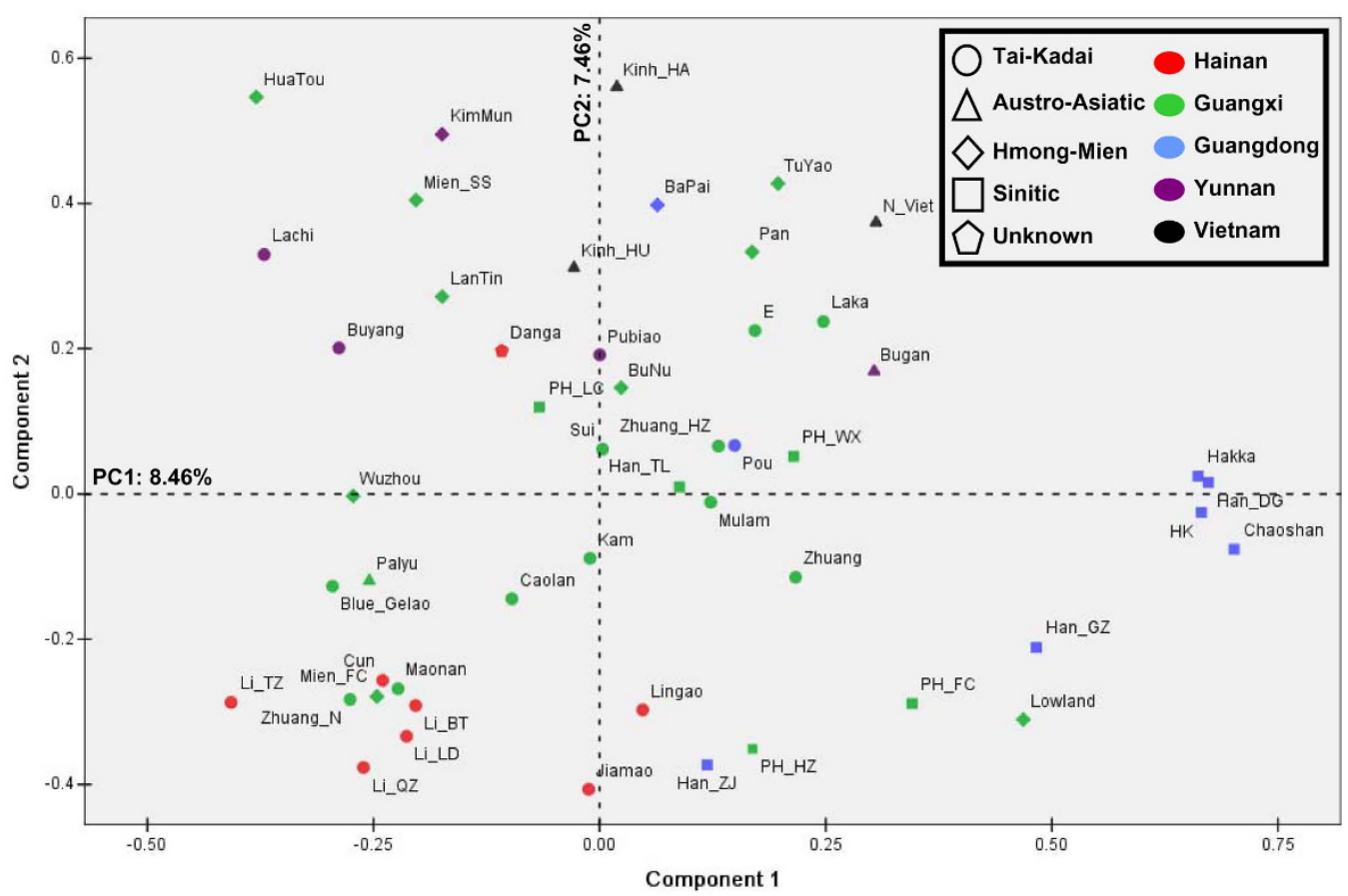

Figure 3 Principle components analysis (PCA) of populations in southern China and Vietnam. The detailed information of 50 populations employed and their haplogroup profiles was indicated in Additional file 2 and 3.

M12, M7e, M7b1, M7 $\mathrm{C}^{*}$, and B4b1 were found to contribute most to the pole consisting of Hainan islanders and the populations from Guangxi (Figure 4).

\section{Dissection of mtDNA haplotypes in Hainan Island}

To analyze mtDNA variation at a finer level, we dissected the haplotype information mainly based on HVSI segment 16080 - 16488 (Figure 2). In general, the Hainan Island populations showed fairly high haplotype diversities compared with Taiwan aborigines or other populations from the mainland (Table 1). Some haplotypes were shared by the $\mathrm{Li}$ and non-Li populations within Hainan Island. In total of 178 haplotypes (16090 - 16365) observed in Hainan islanders, 80 types could be found the identical counterparts in the mainland (see Additional file 4). In addition, the median-joining networks of the most frequent haplogroups (B4b1, B5a, F1a1, R9b, and M7b1) were unable to identify candidate founder types which were suitable to date the related peopling of Hainan Island (see Additional file 5).

For the rest of the three haplogroups (i.e. M12, M7e, and $\left.M 7 c^{*}\right)$ contributing most to the pole of Hainan islanders in PCA (Figure 4), some interesting patterns were observed. With HVS-I motifs as 16223-16234-16258T16290, 16189-16223-16278 and 16166C-16172-1622316311, three lineages assigned within haplogroups M12, $\mathrm{M} \mathrm{C}^{*}$ and $\mathrm{M7e}$, respectively, were restricted in Hainan
Island. Meanwhile, the lineages of 16223-16234-16258T16290 and 16166C-16172-16223-16311 underwent certain sub-differentiation to generate the derived lineages (Figure 2). Moreover, haplogroups M12, M7c* and M7e were more concentrated in the Li populations than those in other non-Li populations (Table 1). Hence, this implies that the three haplogroups might be useful to trace the early peopling of Hainan Island.

\section{Candidate markers for the early peopling of Hainan Island}

As the available phylogeny of haplogroups M12, M7e, and $M 7 \mathrm{C}^{*}$ has not been well depicted at a fine-grained level, we sequenced 14 complete mtDNA genomes: eleven from haplogroup M12, two from haplogroup M7e and one from haplogroup M7c* (Figure 5). The phylogeny of haplogroup M12 was much improved compared to previous work [20,39]. As the result of the earliest split, haplogroup M12b was defined by mutations 11359-16129-16172 and haplogroup M12a was determined by 318-12358. Within haplogroup M12a, haplogroup M12a2 was newly determined by two sequences from Vietnam as sharing mutations 463-16261 and C insertion at 573. Haplogroup M12a1 was defined by the sequence variation motif in HVS-II as 125-127-128 and then was further divided into two clades as M12a1a and M12a1b. All sequences from Hainan Island were 


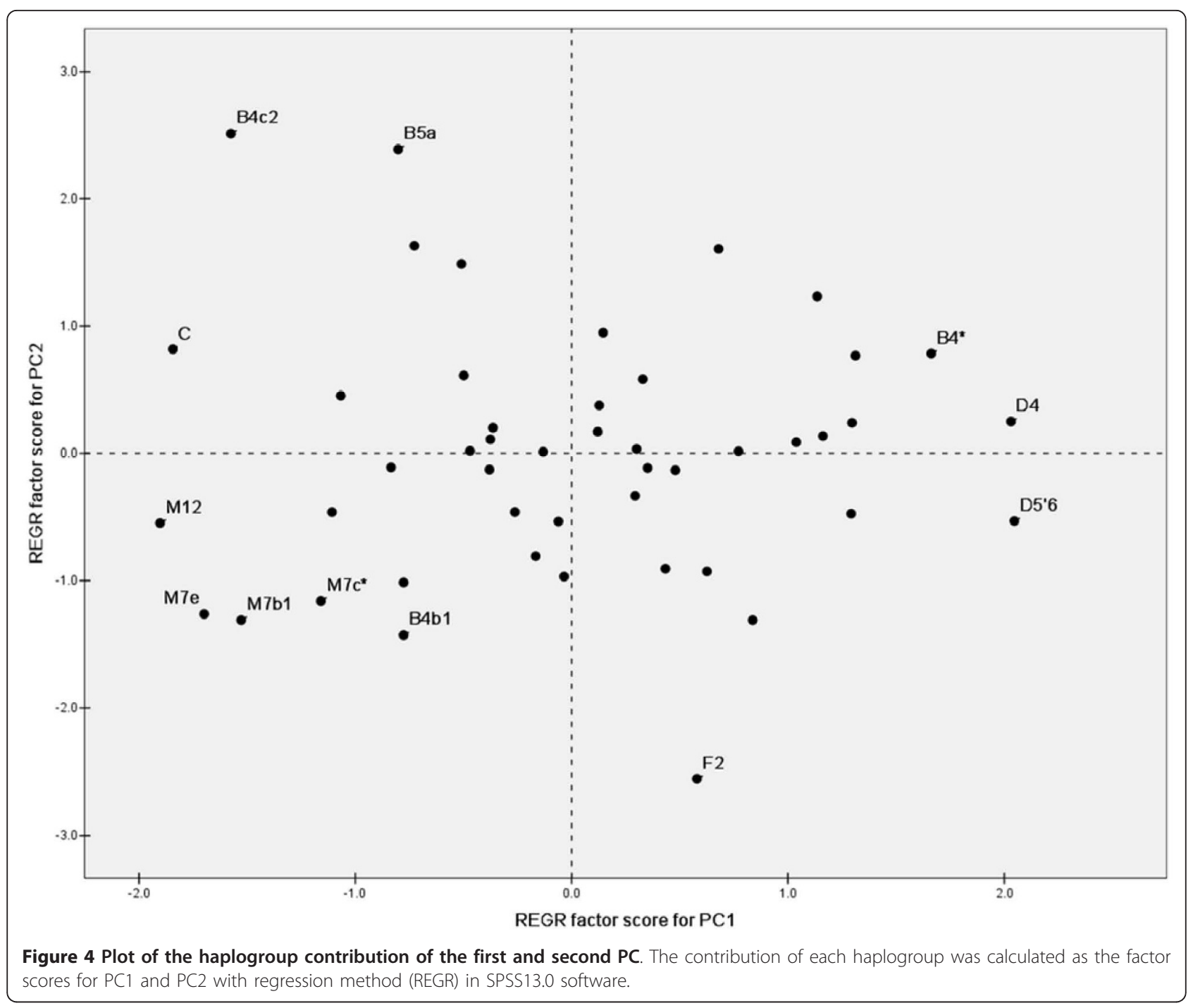

clustered with the sequences from Guangdong and Vietnam into haplogroup M12a1a defined by transitions 15463-15651. The unique lineage of Hainan islanders with HVS-I motif as 16223-16234-16258T-16290 was derived directly from the root of M12a1a suggesting that the modern human colonization of Hainan Island was likely to be associated with the differentiation of M12a1a around 17 - 20 kya.

To characterize the phylogeographic pattern of haplogroup M12, the median-joining network was constructed with all available M12 mtDNAs (Figure 6; see Additional file 6). Haplogroup M12 was widely distributed in southern China, Southeast Asia and the eastern part of India, but relatively concentrated in Yunnan and Hainan Island (Figure 6). The network suggested haplogroup M12 was likely to originate from mainland southern China and Southeast Asia. The estimated expansion time of $\mathrm{M}_{12 \mathrm{a}}{ }^{*}$, which includes the lineages from Hainan Island, was $24.2 \pm 10.0$ kya. The expansion of M12a1-16362 lineages in Hainan Island was estimated as $6.9 \pm 3.4$ kya. The results were largely in agreement with the results from the complete mtDNA genomes (Figure 5). The two ages would be considered as the potential upper $(\sim 24$ kya $)$ and lower $(\sim 7$ kya $)$ limits for the peopling of Hainan Island represented by haplogroup M12, respectively.

The phylogeny of haplogroup M7e based on complete mtDNA genomes revealed that the sequence (Li241) with 16166C-16172-16223-16311 was directly derived from the root of haplogroup M7e around 6.5 - 8.0 kya (Figure 5). As the lineages with the proto haplotypes defined by HVS-I variations 16172-16223-16311 were mainly found in southern China and Vietnam (see Additional file 7), the colonization of Hainan Island represented by haplogroup M7e would be probably from this region around $15.1 \pm 11.5$ kya (Figure 7 ). However, as 


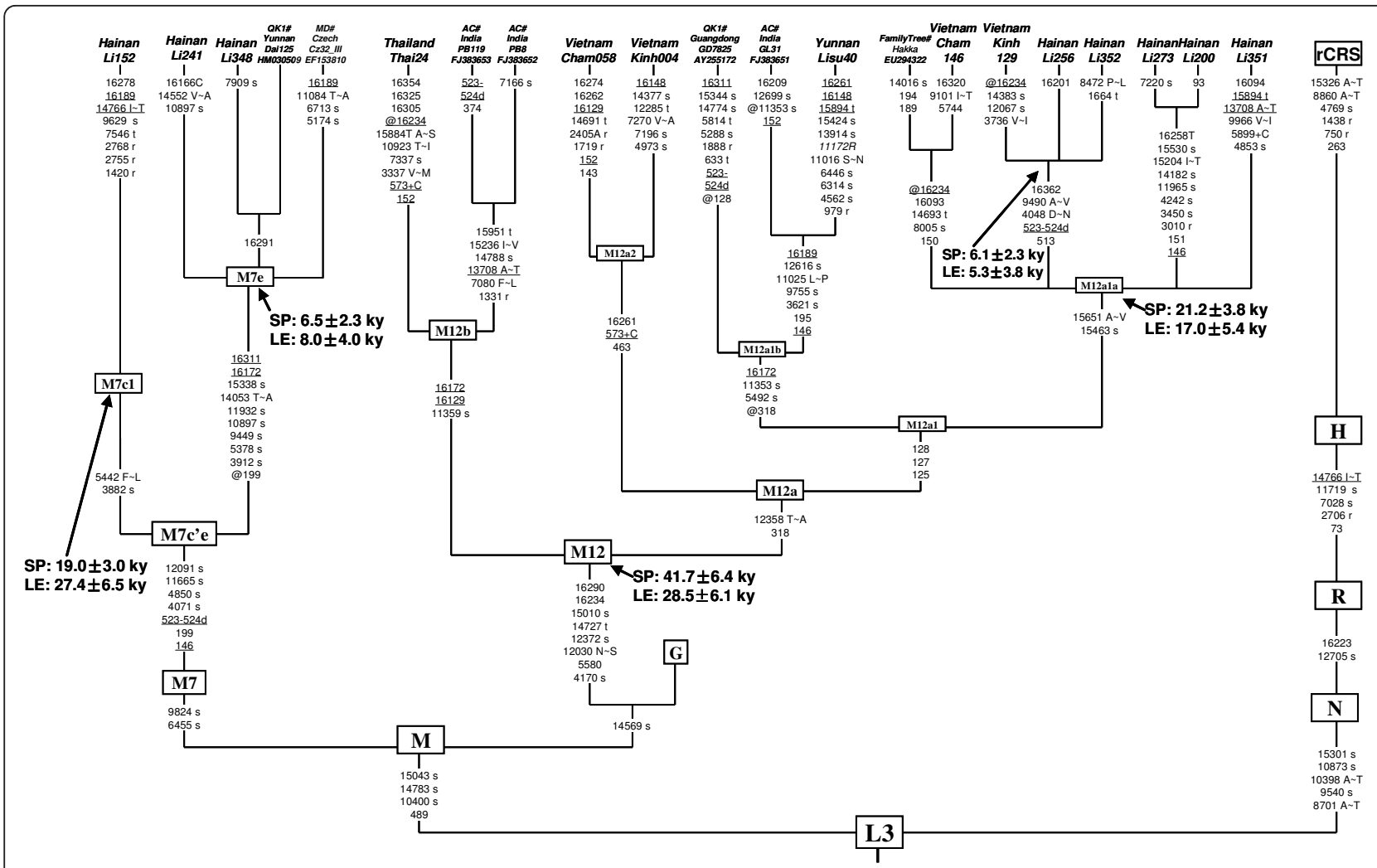

Figure 5 Reconstructed phylogenetic tree of 21 complete mtDNA genome sequences from haplogroups M12 and M7c'e. The six reported sequences were taken from the literature and were further labeled by the symbols MD [18], AC [39], QK1 [20], and QK2 [28] followed by "\#", the geographic locations, and the sample codes or the access numbers in GenBank. One sequence (Accession No. EU294322) submitted by "Family Tree DNA" was retrieved from GenBank. Haplogroup age estimates ( \pm standard errors) are indicated at the branch roots in terms of the calibrated mutation rate with symbols as SP [58] and LE [66], respectively. Mutations are transitions at the respective nucleotide position unless otherwise specified. Letters following positions indicate transversions. Recurrent mutations are underlined. +: insertion; d: deletion; @: back-mutation. "R" specifies heteroplasmic status A/G and was also noted in italic. Amino acid replacements are specified by single-letter code; $\mathrm{s}$, synonymous replacements; $t$, change in transfer RNA; $r$, change in ribosomal RNA gene.

the network of haplogroup M7e was not in the ideally star-like structure, the time estimates with a huge standard error should be treated with caution. When we estimated the expansion time of M7e without the Hainan data, the age $(9.4 \pm 5.9$ kya; Figure 7$)$ seemed more compatible with the result based on mtDNA genomes (Figure 5).

For the sequences of M7c* with HVS-I motif as 1618916223-16278, the complete mtDNA sequence (Li152) could be assigned into M7c1 but did not cluster with any known lineages of M7c1. This pattern implied that the related peopling of Hainan Island was likely to be traced back to the initial differentiation of haplogroup M7c1 as early as $\sim 18-27$ kya (Figure 5 ).

\section{Discussion}

In general, the mtDNA haplogroup profiles of Hainan islanders are similar to the profiles of the populations from mainland southern China. This pattern is consistent with the previous work on NRY [4,40-43]. It suggests the Hainan islanders should have derived from mainland southern China and/or have had a common origin with the populations from this region [30]. Especially, most Hainan islanders were clustered with some populations from Guangxi (Figure 3). This pattern was also reflected by the genome-wide data: the Jiamao population in Hainan Island was clustered with the Zhuang population (i.e. the dominant minority ethnic group in Guangxi) as a branch in the tree of the "PanAsian" [44]. Thus, the ancestors of the Li populations were likely from Guangxi.

As the prevailing haplotype sharing has been found between the Hainan islanders and the populations from the mainland, the role of the recent gene flow from the mainland in shaping the maternal pool of Hainan islanders can not be ignored. This result is in agreement with the archaeological research, which revealed that the tight links between Hainan Island and mainland southern China existed during the Neolithic period $[5,10,13]$. Meanwhile, some haplotypes were shared by the Li 


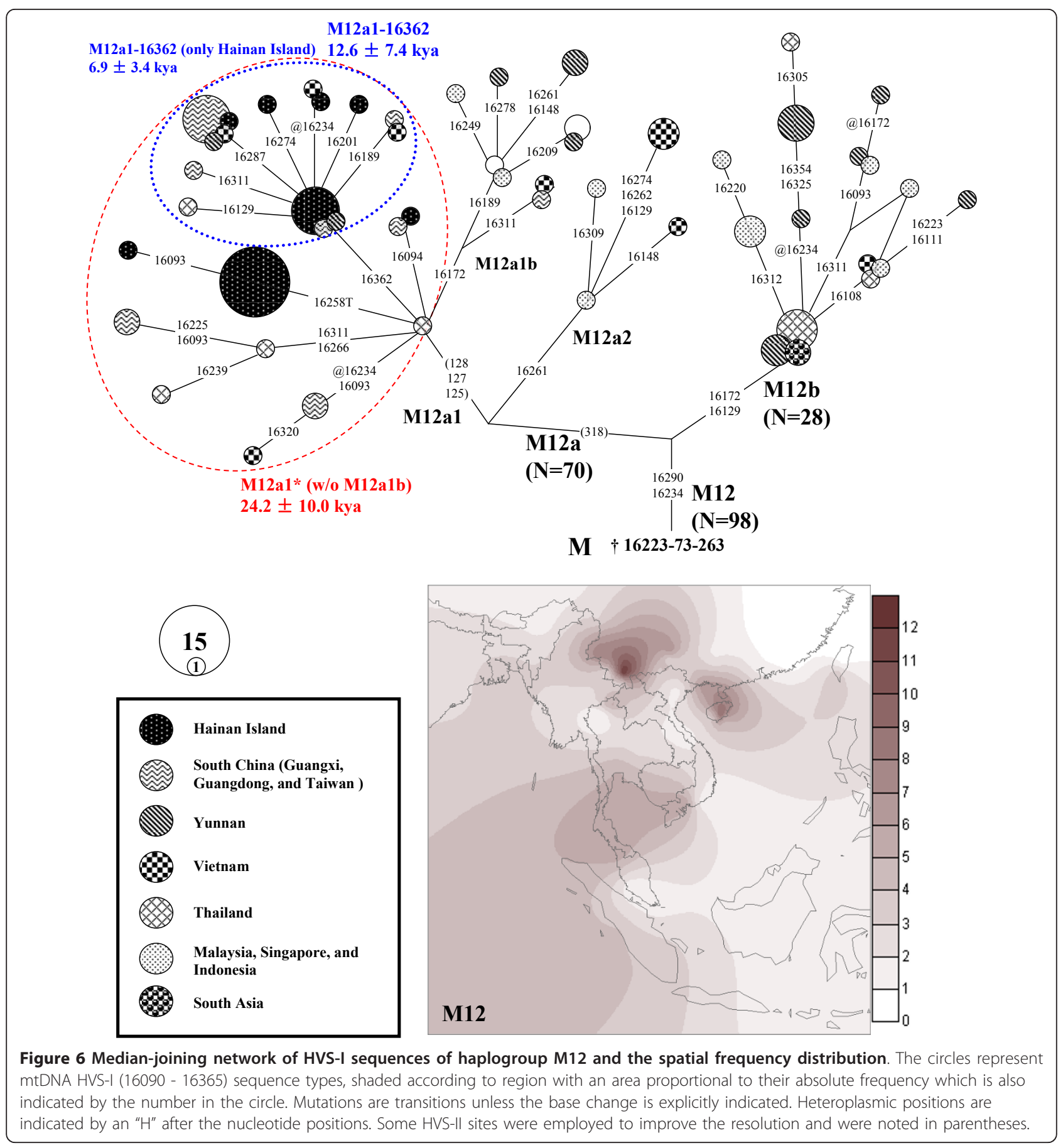

(original aborigines) and the non-Li (recent immigrants) populations (Figure 2). It suggests that intermarriages among different populations might be common and could strengthen the effect of recent demographic events. As a result, although certain haplogroups in Hainan islanders present the star-like phylogeny in the network (e.g. B5a and M7b1, Figure 2; see Additional file 5) and the characteristics of the candidate founders [45], whether their expansion time estimates (Table 2) could be associated with the early peopling of Hainan Island is still elusive.

To trace the early peopling of Hainan Island, we paid more attention to haplogroups $\mathrm{M} 12 \mathrm{M} 7 \mathrm{c1}^{*}$, and $\mathrm{M7e}$, because: 1) they have relatively high frequencies in Hainan Island and are relatively concentrated in the $\mathrm{Li}$ populations; 2) some lineages within these haplogroups are only found in Hainan Island; 3) certain sub-differentiation within these haplogroups are observed. Detailed 


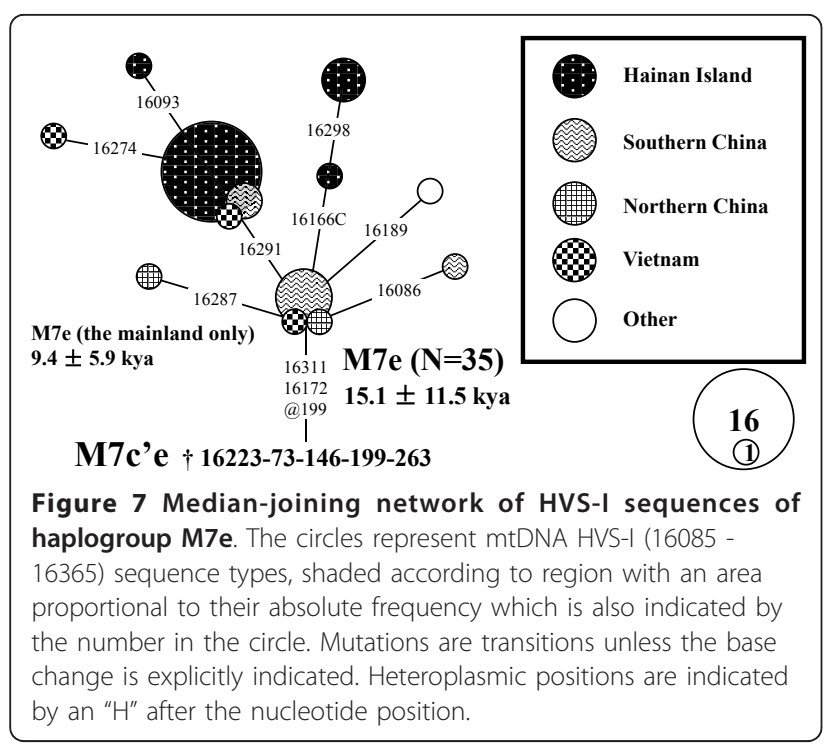

phylogeographic analyses based on mtDNA genomes suggested the initial peopling of Hainan Island was likely to be around 7 - 27 kya (Figure 5 - 6) when Hainan Island was connected with the mainland southern China and/or northern Vietnam [3,9]. The long-standing connection between Hainan Island and the mainland from the LGM to 6 - 7 kya [3,9] could provide the opportunity for some of the dispersals of modern human. Our results are largely in agreement with the time estimates from NRY [4] and are supported by the recent archeological findings [5-8]. However, as mentioned above, the gene pool of Hainan islanders was likely to be affected by the recent immigrants from the mainland. To pin down the recent gene flow and the ancient components in detail, it is necessary to improve the resolution of molecular markers, together with extensive sampling, and even to employ genome-wide autosomal markers, which could be the future direction and would provide more details about the peopling of Hainan Island.

\section{Conclusions}

Combining the fresh data of the mtDNA variation of the $285 \mathrm{Li}$ individuals and those from previous study, we not only help to further understand the mtDNA phylogeny in Hainan Island but also provide deeper insights into the peopling of Hainan Island. Although some genetic differentiations from the populations in the mainland did emerge, in general, the mtDNA phylogeny in Hainan Island was represented as a subset in the context of East Asian and Southeast Asian. The ancestors of the Li people were likely from the populations in mainland southern China, especially in Guangxi. The recent gene flow from the mainland might play important roles in shaping the maternal pool of Hainan islanders. Based on the mtDNA genome sequencing, the phylogeographic analyses of haplogroups M12, M7e, and M7c1* suggested that the related immigration from mainland southern China and Vietnam could be trace back to around $7-27 \mathrm{kya}$, which largely corresponds to the results from NRY and archaeology.

\section{Methods}

\section{Population samples and DNA extraction}

In total, we collected samples from 285 unrelated $\mathrm{Li}$ individuals residing in Hainan Island (Figure 2): 86 from Qiongzhong Li and Miao Autonomous County (Li-QZ); 99 from Baoting Li and Miao Autonomous County (LiBT); and 100 from Ledong Li Autonomous County (LiLD). All subjects were interviewed to ascertain their ethnic affiliations and to obtain informed consent before blood collection. Comparative mtDNA data from southern China and Vietnam were taken from previous published literature (see Additional file 2). Genomic DNA was extracted from whole blood samples by the standard phenol/chloroform methods.

\section{MtDNA typing}

The mtDNA control region sequences were amplified by the PCR method previously reported [46]. HVS-I (minimum length sequenced was nucleotide positions (np) 16080-16569; maximum length sequenced np 1600116569) and HVS-II (minimum length sequenced np 1-207; maximum length sequenced np 1-575) were sequenced in all samples as described elsewhere [47]. We performed haplogroup-specific control region motif recognition and

Table 2 Coalescence ages of the most frequent mtDNA haplogroups in Hainan Island

\begin{tabular}{|c|c|c|c|c|c|c|c|c|c|c|}
\hline \multirow[b]{2}{*}{ Haplogroups } & \multirow{2}{*}{$\begin{array}{c}\text { Total } \\
\text { Individuals }\end{array}$} & \multicolumn{9}{|c|}{$\mathrm{Li}$} \\
\hline & & $\rho$ & $\sigma$ & $\mathrm{T}$ & $\Delta \mathrm{T}$ & Individuals & $\rho$ & $\sigma$ & $\mathrm{T}$ & $\Delta \mathrm{T}$ \\
\hline $\mathrm{B} 5 \mathrm{a}$ & 37 & 1.03 & 0.32 & 19.4 & 5.9 & 30 & 1.07 & 0.35 & 20.1 & 6.6 \\
\hline B4b1 & 31 & 0.45 & 0.26 & 8.5 & 4.9 & 29 & 0.45 & 0.27 & 8.4 & 5.2 \\
\hline F1a1-16399 & 31 & 0.13 & 0.07 & 2.4 & 1.2 & 30 & 0.13 & 0.07 & 2.5 & 1.3 \\
\hline M7b1 & 31 & 0.45 & 0.22 & 8.5 & 4.2 & 24 & 0.54 & 0.29 & 10.2 & 5.0 \\
\hline M12 & 28 & 0.61 & 0.40 & 11.4 & 7.6 & 26 & 0.54 & 0.39 & 10.1 & 7.4 \\
\hline $\mathrm{R} 9 \mathrm{~b}$ & 21 & 1.67 & 1.00 & 31.4 & 18.8 & 19 & 1.21 & 1.10 & 31.7 & 20.7 \\
\hline M7e & 20 & 1.00 & 0.82 & 18.8 & 15.4 & 16 & 1.00 & 0.78 & 18.8 & 14.6 \\
\hline
\end{tabular}


(near-) matching search with the published mtDNA data to assign each mtDNA into specific, named haplogroups [46]. Then we selected certain mtDNAs from sequences having similar HVS motifs to genotype the related diagnostic sites in the coding region to confirm their haplogroup status (see Additional file 1). Moreover, 14 whole mtDNA genomes were sequenced following protocols reported elsewhere [48-50]. The sequences generated in this study have been deposited in GenBank database (Accession Nos. HQ156470-HQ156754 for HVS and HQ157971-HQ157984 for mtDNA genome sequences).

Sequences were edited and aligned by Lasergene (DNAStar Inc., Madison, Wisconsin, USA) and mutations were scored relative to the revised Cambridge sequence (rCRS) [51]. For the length variants in the control region, we followed the rules proposed by Bandelt and Parson (2008) [52]. The transition at 16519 and the C-length polymorphisms in regions 16180-16193 and 303-315 were disregarded in the analyses. The classification of the mutations of each mtDNA genomes was performed with mtDNA GeneSyn $1.0 \mathrm{http} / / / \mathrm{www}$. ipatimup.pt/downloads/mtDNAGeneSyn.zip [53]. To avoid any nomenclature conflicts, we followed the criterion of PhyloTree (http://www.phylotree.org, mtDNA tree Build 10) [54] and the recent updating mtDNA phylogeny in East Asia [28].

\section{Data analyses}

For HVS data, we constructed the median-joining network using Network 4.510 http://www.fluxus-engineering.com/sharenet.htm [55]. The coalescent age of a haplogroup of interest was estimated by statistics $\rho \pm$ $\sigma[56,57]$ and the rate of 18,845 years per transition for control region (16090-16365) [58] was used (Table 2). Principal components analysis (PCA) followed the method developed by Richards et al. with SPSS13.0 software (SPSS) [38]. Analysis of molecular variance (AMOVA) was computed with the package Arlequin $3.11 \mathrm{http}: / / \mathrm{cmpg}$.unibe.ch/software/arlequin3/ [59]. The counter map of spatial frequency was created by using the Kriging algorithm of the Surfer 8.0 package (Golden Software Inc., Golden, Colorado, USA) [60]. To detect the recent gene flow, haplotypes sharing analyses between the Hainan islanders and the populations from the mainland were carried out based on phylogeny [61].

For complete mtDNA sequences, the phylogeny was reconstructed manually and checked by Network 4.510 . Six reported sequences were employed for tree reconstructed (Figure 5). To estimate the coalescence time of haplogroup M7c1, additional 13 complete mtDNA genomes from the published literature (Accession Nos. EF153823, EF397561, EU007890, EU597541, AP008755,
AP008336, AP008647, AP008886, AP010681, AP010827, HM030514, HM030523, and HM030547) [18,27, 28,62-65] were employed but not displayed in the tree. The coalescent age was also estimated by statistics $\rho \pm \sigma[56,57]$. The recent calibrated rates for the entire mtDNA genome [58] and for only the synonymous mutation [66] were adopted, respectively (Figure 5).

\section{Additional material}

\author{
Additional file 1: mtDNA control and coding region information of \\ $\mathbf{2 8 5} \mathrm{Li}$ individuals from three populations. The data provide the \\ markers examined in the subjects of the present study. \\ Additional file 2: Information of comparative populations used in \\ this study. The information includes ethnic groups, sample sizes, \\ geographic locations, language affinities, and the references for all \\ additional files. \\ Additional file 3: mtDNA haplogroup frequencies of 50 populations \\ from Hainan Island, mainland southern China, and Vietnam. The \\ data were used in the PCA and AMOVA. \\ Additional file 4: Haplotype sharing between Hainan islanders and \\ the populations in the neighboring mainland region. The haplotype \\ sharing was calculated with the fragment 16090 - 16365 in HVS-I. \\ Additional file 5: Median-joining network of HVS-I sequences of \\ haplogroups B4b1, B5a, F1a1, R9b, and M7b1. The information refers \\ sequences from populations in Hainan Island and its neighboring regions \\ in the mainland. \\ Additional file 6: mtDNA sequences of haplogroup M12. The \\ information refers 98 sequences of haplogroup M12 used to reconstruct \\ the median-joining network. \\ Additional file 7: mtDNA sequences of haplogroup M7e. The \\ information refers 35 sequences of haplogroup M7e used to reconstruct \\ the median-joining network.
}

\section{Acknowledgements}

We are grateful to all the donors for providing blood samples. We thank Chun-Ling Zhu, Shi-Fang Wu, and Ji-Shan Wang for technical assistance and Yan-Tao Yao for providing the map of Hainan Island. And we thank Dr. Chad L. Samuelsen for language editing. This study was supported by grants from National Natural Science Foundation of China (30621092 and 30900797), and Bureau of Science and Technology of Yunnan Province (2009Cl119).

\section{Author details}

${ }^{1}$ State Key Laboratory of Genetic Resources and Evolution, Kunming Institute of Zoology, Chinese Academy of Sciences, Kunming, P.R. China. ${ }^{2}$ School of Life Science, University of Science and Technology of China, Hefei, P.R. China. ${ }^{3}$ KIZ/CUHK Joint Laboratory of Bioresources and Molecular Research in Common Diseases, Kunming, P.R. China. ${ }^{4}$ Laboratory for Conservation and Utilization of Bio-resources, Yunnan University, Kunming, P.R. China. ${ }^{5}$ Graduate School of the Chinese Academy of Sciences, Beijing, P.R. China. ${ }^{6}$ Current address: Program in Neuroscience, SUNY at Stony Brook, Stony Brook, New York, USA.

\section{Authors' contributions}

MSP: contributed to the experiment work, data analysis and manuscript writing; JDH: carried out the experiment work and data analysis; HXL: performed the experiment work and commented the manuscript; YPZ: designed the study and prepared the manuscript; and all authors have read and approved the final manuscript.

Received: 30 September 2010 Accepted: 15 February 2011 Published: 15 February 2011 


\section{References}

1. Clark PU, Dyke AS, Shakun JD, Carlson AE, Clark J, Wohlfarth B, Mitrovica JX, Hostetler SW, McCabe AM: The Last Glacial Maximum. Science 2009, 325:710-714.

2. Huang ZG, Zhang WQ, Chai FX, Xu QH: On the lowest sea level during the culmination of the lastest glacial period in South China. Acta Geogr Sin 1995, 50:385-393.

3. Yao YT, Harff J, Meyer M, Zhan WH: Reconstruction of paleocoastlines for the northwestern South China Sea since the Last Glacial Maximum. Sci China Ser D-Earth Sci 2009, 52:1127-1136.

4. Li D, Li H, Ou C, Lu Y, Sun Y, Yang B, Qin Z, Zhou Z, Li S, Jin L: Paternal genetic structure of Hainan aborigines isolated at the entrance to East Asia. PLOS ONE 2008, 14:e2168.

5. Hao SD, Wang DX: Hainan archaeology: retrospect and prospect. Kaogu 2003, 291-299.

6. Li CR, Li Z, Wang DX, Hao SD, Wang MZ, Jiang B, Huang ZX, Fang XL: Some stone artifacts discovered in Changjiang, Hainan. Acta Anthropol $\sin 2008,27: 66-69$

7. Li Z, Li CR, Wang DX: Paleolithic archaeology in Hainan Province. In Proceedings of the Eleventh Annual Meeting of the Chinese Society of Vertebrate Paleontology. Edited by: Dong W. Beijing: China Ocean Press; 2008:167-172.

8. Wang DX: The Hunyaling zoolite of Changjiang Country. In Archaeology Almanac (1999). Edited by: Chinese Society of Archaeology. Beijing: Culture Relics Publishing House; 2001:267-268.

9. Zhao HT, Wang LR, Yuan JY: Origin and time of Qiongzhou Strait. Mar Geol \& Quaternary Geol 2007, 27:33-40.

10. Yan J: Eco-environmental changes in Hainan Island Beijing: Science Press; 2008.

11. Du R, Yip VF: Ethnic groups in China Beijing and New York: Science Press; 1993.

12. Ostapirat W: Kra-Dai and Austronesian: notes on phonological correspondences and vocabulary distribution. In The peopling of East Asia: putting together archaeology, linguistics and genetics. Edited by: Sagart L, Blench R, Sanchez-Mazas A. London and New York: RoutledgeCurzon; 2005:107-131.

13. Wang HP: The Neolithic archaeological discoveries and researches in Hainan. J Hainan Normal Univ 1990, 81-89.

14. Underhill PA, Kivisild $T$ : Use of $Y$ chromosome and mitochondrial DNA population structure in tracing human migrations. Annu Rev Genet 2007, 41:539-564.

15. Li H, Wen B, Chen SJ, Su B, Pramoonjago P, Liu YF, Pan SL, Qin ZD, Liu W Cheng $X$, et al: Paternal genetic affinity between western Austronesians and Daic populations. BMC Evol Biol 2008, 8:146.

16. Ingman M, Kaessmann H, Pääbo S, Gyllensten U: Mitochondrial genome variation and the origin of modern humans. Nature 2000, 408:708-713.

17. Dancause KN, Chan CW, Arunotai NH, Lum JK: Origins of the Moken Sea Gypsies inferred from mitochondrial hypervariable region and whole genome sequences. J Hum Genet 2009, 54:86-93.

18. Derenko M, Malyarchuk B, Grzybowski T, Denisova G, Dambueva I, Perkova M, Dorzhu C, Luzina F, Lee HK, Vanecek T, et al: Phylogeographic analysis of mitochondrial DNA in northern Asian Populations. Am J Hum Genet 2007, 81:1025-1041.

19. Hill C, Soares P, Mormina M, Macaulay V, Meehan W, Blackburn J, Clarke D, Raja JM, Ismail P, Bulbeck D, et al: Phylogeography and ethnogenesis of aboriginal Southeast Asians. Mol Biol Evol 2006, 23:2480-2491.

20. Kong QP, Bandelt HJ, Sun C, Yao YG, Salas A, Achilli A, Wang CY, Zhong L, Zhu CL, Wu SF, et al: Updating the East Asian mtDNA phylogeny: a prerequisite for the identification of pathogenic mutations. Hum $\mathrm{Mol}$ Genet 2006, 15:2076-2086.

21. Kong QP, Yao YG, Sun C, Bandelt HJ, Zhu CL, Zhang YP: Phylogeny of East Asian mitochondrial DNA lineages inferred from complete sequences. Am J Hum Genet 2003, 73:671-676.

22. Macaulay V, Hill C, Achilli A, Rengo C, Clarke D, Meehan W, Blackburn J, Semino $O$, Scozzari $R$, Cruciani $F$, et al: Single, rapid coastal settlement of Asia revealed by analysis of complete mitochondrial genomes. Science 2005, 308:1034-1036.

23. Peng MS, Quang HH, Dang KP, Trieu AV, Wang HW, Yao YG, Kong QP, Zhang YP: Tracing the Austronesian footprint in Mainland Southeast Asia: a perspective from mitochondrial DNA. Mol Biol Evol 27:2417-2430
24. Soares P, Trejaut JA, Loo JH, Hill C, Mormina M, Lee CL, Chen YM, Hudjashov G, Forster P, Macaulay V, et al: Climate change and postglacial human dispersals in Southeast Asia. Mol Biol Evol 2008, 25:1209-1218.

25. Tabbada KA, Trejaut J, Loo JH, Chen YM, Lin M, Mirazon-Lahr M, Kivisild T, De Ungria MC: Philippine mitochondrial DNA diversity: a populated viaduct between Taiwan and Indonesia? Mol Biol Evol 2010, 27:21-31.

26. Trejaut JA, Kivisild T, Loo JH, Lee CL, He CL, Hsu CJ, Li ZY, Lin M: Traces of archaic mitochondrial lineages persist in Austronesian-speaking Formosan populations. PLOS Biol 2005, 3:1362-1372.

27. Tanaka M, Cabrera VM, González AM, Larruga JM, Takeyasu T, Fuku N, Guo LJ, Hirose R, Fujita Y, Kurata M, et al: Mitochondrial genome variation in Eastern Asia and the peopling of Japan. Genome Res 2004, 14:1832-1850.

28. Kong QP, Sun C, Wang HW, Zhao M, Wang WZ, Zhong L, Hao XD, Pan H, Wang SY, Cheng YT, et al: Large-scale mtDNA screening reveals a surprising matrilineal complexity in East Asia and its implications to the peopling of the region. Mol Biol Evol 2011, 28:513-522.

29. Gan RJ, Pan SL, Mustavich LF, Qin ZD, Cai XY, Qian J, Liu CW, Peng JH, Li SL, Xu JS, et al: Pinghua population as an exception of Han Chinese's coherent genetic structure. J Hum Genet 2008, 53:303-313.

30. Li H, Cai X, Winograd-Cort ER, Wen B, Cheng X, Qin Z, Liu W, Liu Y, Pan S, Qian J, et al: Mitochondrial DNA diversity and population differentiation in Southern East Asia. Am J Phys Anthropol 2007, 134:481-488.

31. Wang WZ, Wang CY, Cheng YT, Xu AL, Zhu CL, Wu SF, Kong QP, Zhang YP: Tracing the origins of Hakka and Chaoshanese by mitochondrial DNA analysis. Am J Phys Anthropol 2010, 141:124-130

32. Wen B, Li H, Gao S, Mao X, Gao Y, Li F, Zhang F, He Y, Dong Y, Zhang Y, et al: Genetic structure of Hmong-Mien speaking populations in East Asia as revealed by mtDNA lineages. Mol Biol Evol 2005, 22:725-734.

33. Wen B, Li H, Lu D, Song X, Zhang F, He Y, Li F, Gao Y, Mao X, Zhang L, et al: Genetic evidence supports demic diffusion of Han culture. Nature 2004, 431:302-305

34. Yao YG, Nie L, Harpending H, Fu YX, Yuan ZG, Zhang YP: Genetic relationship of Chinese ethnic populations revealed by mtDNA sequence diversity. Am J Phys Anthropol 2002, 118:63-76.

35. Kivisild T, Tolk HV, Parik J, Wang YM, Papiha SS, Bandelt HJ, Villems R: The emerging limbs and twigs of the East Asian mtDNA tree. Mol Biol Evol 2002, 19:1737-1751.

36. Yao YG, Kong QP, Bandelt HJ, Kivisild T, Zhang YP: Phylogeographic differentiation of mitochondrial DNA in Han Chinese. Am J Hum Genet 2002, 70:635-651.

37. Irwin JA, Saunier JL, Strouss KM, Diegoli TM, Sturk KA, O'Callaghan JE, Paintner CD, Hohoff C, Brinkmann B, Parsons TJ: Mitochondrial control region sequences from a Vietnamese population sample. Int J Legal Med 2008, 122:257-259.

38. Richards M, Macaulay V, Torroni A, Bandelt HJ: In search of geographical patterns in European mitochondrial DNA. Am J Hum Genet 2002, 71:1168-1174.

39. Chandrasekar A, Kumar S, Sreenath J, Sarkar BN, Urade BP, Mallick S, Bandopadhyay SS, Barua P, Barik SS, Basu D, et al: Updating phylogeny of mitochondrial DNA macrohaplogroup M in India: dispersal of modern human in South Asian corridor. PLOS ONE 2009, 4:e7447.

40. Sun Y, Yang B, Ou C, Chen L, Su Z, Li D: Investigation into the origin of Li ethnic group in China by genetic analysis of $\mathrm{Y}$ chromosome single nucleotide polymorphism. China Trop Med 2007, 7:1527-1529.

41. Sun Y, Yang B, Ou C, Zhou Z, Su Z, Li D: Origins of the Three Minority Populations in Hainan Island as Seen from Y-SNP. Sci \&Technol Rev 2007, 25:44-47.

42. Yang B, Li D, Sun Y, Ou C, Ying D: Genetic analysis of Y-chromosomal single nucleotide polymorphoism in three banches of Li ethnic groups in Hainan Province. China Trop Med 2007, 7:341-356.

43. Li D, Sun Y, Lu Y, Mustavich LF, Ou C, Zhou Z, Li S, Jin L, Li H: Genetic origin of Kadai-speaking Gelong people on Hainan island viewed from $Y$ chromosomes. J Hum Genet 2010, 55:462-468.

44. Abdulla MA, Ahmed I, Assawamakin A, Bhak J, Brahmachari SK, Calacal GC, Chaurasia A, Chen $\mathrm{CH}$, Chen JM, Chen YT, et al: Mapping human genetic diversity in Asia. Science 2009, 326:1541-1545.

45. Richards M, Macaulay V, Hickey E, Vega E, Sykes B, Guida V, Rengo C, Sellitto D, Cruciani F, Kivisild $T$, et al: Tracing European founder lineages in the near eastern mtDNA pool. Am J Hum Genet 2000, 67:1251-1276 
46. Yao YG, Kong QP, Wang CY, Zhu CL, Zhang YP: Different matrilineal contributions to genetic structure of ethnic groups in the Silk Road region in China. Mol Biol Evol 2004, 21:2265-2280.

47. Yao YG, Kong QP, Man XY, Bandelt HJ, Zhang YP: Reconstructing the evolutionary history of China: a caveat about inferences drawn from ancient DNA. Mol Biol Evol 2003, 20:214-219.

48. Fendt L, Zimmermann B, Daniaux M, Parson W: Sequencing strategy for the whole mitochondrial genome resulting in high quality sequences. BMC Genomics 2009, 10:139.

49. Wang HW, Jia XY, Ji YL, Kong QP, Zhang QJ, Yao YG, Zhang YP: Strikingly different penetrance of LHON in two Chinese families with primary mutation G11778A is independent of mtDNA haplogroup background and secondary mutation G13708A. Mutat Res 2008, 643:48-53.

50. Zhao M, Kong QP, Wang HW, Peng MS, Xie XD, Wang WZ, Duan JG, Cai MC, Zhao SN, et al: Mitochondrial genome evidence reveals successful Late Paleolithic settlement on the Tibetan Plateau. Proc Natl Acad Sci USA 2009, 106:21230-21235.

51. Andrews RM, Kubacka I, Chinnery PF, Lightowlers RN, Turnbull DM, Howell N: Reanalysis and revision of the Cambridge reference sequence for human mitochondrial DNA. Nat Genet 1999, 23:147-147.

52. Bandelt HJ, Parson W: Consistent treatment of length variants in the human mtDNA control region: a reappraisal. Int I Legal Med 2008, 122:11-21

53. Pereira L, Freitas F, Fernandes V, Pereira JB, Costa MD, Costa S, Maximo V, Macaulay V, Rocha R, Samuels DC: The diversity present in 5140 human mitochondrial genomes. Am J Hum Genet 2009, 84:628-640.

54. van Oven M, Kayser M: Updated comprehensive phylogenetic tree of global human mitochondrial DNA variation. Hum Mutat 2009, 30 E386-E394.

55. Bandelt $H J$, Forster $P$, Rohl A: Median-joining networks for inferring intraspecific phylogenies. Mol Biol Evol 1999, 16:37-48.

56. Forster P, Harding R, Torroni A, Bandelt HJ: Origin and evolution of native American mtDNA variation: a reappraisal. Am J Hum Genet 1996, 59:935-945.

57. Saillard J, Forster P, Lynnerup N, Bandelt HJ, Norby S: mtDNA variation among Greenland Eskimos: the edge of the Beringian expansion. Am J Hum Genet 2000, 67:718-726.

58. Soares P, Ermini L, Thomson N, Mormina M, Rito T, Rohl A, Salas A, Oppenheimer S, Macaulay V, Richards MB: Correcting for purifying selection: an improved human mitochondrial molecular clock. Am J Hum Genet 2009, 84:740-759.

59. Excoffier L, Laval G, Schneider S: Arlequin ver. 3.0: an integrated software package for population genetics data analysis. Evol Bioinform Online 2005, $1: 47-50$

60. Cavalli-Sforza LL, Menozzi P, Piazza A: The history and geography of human genes Princeton: Princeton University Press; 1994

61. Achilli A, Olivieri A, Pala M, Metspalu E, Fornarino S, Battaglia V, Accetturo M, Kutuev I, Khusnutdinova E, Pennarun E, et al: Mitochondrial DNA variation of modern Tuscans supports the near eastern origin of Etruscans. Am J Hum Genet 2007, 80:759-768.

62. Bilal E, Rabadan R, Alexe G, Fuku N, Ueno H, Nishigaki Y, Fujita Y, Ito M, Arai $Y$, Hirose $N$, et al: Mitochondrial DNA haplogroup D4a is a marker for extreme longevity in Japan. PLOS ONE 2008, 3:e2421.

63. Hartmann A, Thieme M, Nanduri LK, Stempfl T, Moehle C, Kivisild T, Oefner PJ: Validation of microarray-based resequencing of 93 worldwide mitochondrial genomes. Hum Mutat 2009, 30:115-122.

64. Ingman M, Gyllensten U: Rate variation between mitochondrial domains and adaptive evolution in humans. Hum Mol Genet 2007, 16:2281-2287.

65. Nohira C, Maruyama S, Minaguchi K: Phylogenetic classification of Japanese mtDNA assisted by complete mitochondrial DNA sequences. Int J Legal Med 2010, 124:7-12.

66. Loogväli EL, Kivisild T, Margus T, Villems R: Explaining the imperfection of the molecular clock of hominid mitochondria. PLoS ONE 2009, 4:e8260

doi:10.1186/1471-2148-11-46

Cite this article as: Peng et al.: Tracing the legacy of the early Hainan Islanders- a perspective from mitochondrial DNA. BMC Evolutionary Biology 2011 11:46.

\section{Submit your next manuscript to BioMed Central and take full advantage of:}

- Convenient online submission

- Thorough peer review

- No space constraints or color figure charges

- Immediate publication on acceptance

- Inclusion in PubMed, CAS, Scopus and Google Scholar

- Research which is freely available for redistribution

Submit your manuscript at www.biomedcentral.com/submit 